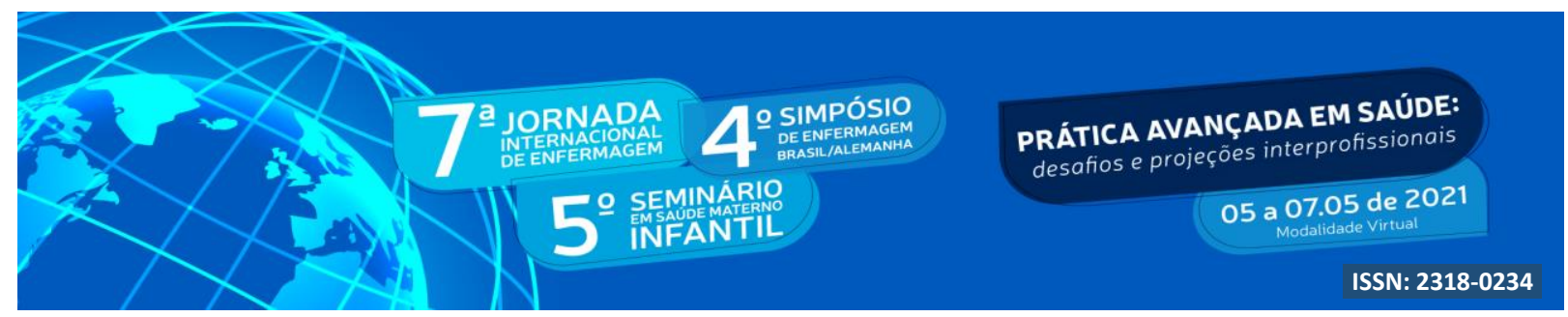

DOI: http://doi.org/10.48195/jie2021-028

\title{
A IMPORTÂNCIA DAS ORIENTAÇÕES À PUÉRPERA E FAMILIA EM ALOJAMENTO CONJUNTO: RELATO DE EXPERIÊNCIA ${ }^{1}$
}

\author{
Gabriéli da Silva² ${ }^{2}$ Gloria Cogo ${ }^{3}$; Flavia Camef ${ }^{4}$; Lenise da Silva ${ }^{5}$
}

\begin{abstract}
RESUMO
Este estudo teve como objetivo relatar uma experiência acadêmica com puérperas e familiares em alojamento conjunto refletindo a importância das orientações sobre os cuidados com o recém-nascido e o autocuidado da mulher. Trata-se de um relato de experiência desenvolvido durante as atividades praticas da disciplina de saúde da mulher. Para um embasamento teórico nas discussões foi realizada busca na base de dados Literatura Latino-americana e do Caribe em Ciências da Saúde. A vivência acadêmica fez com que as acadêmicas a partir da anamnese e da escuta ativa percebessem as principais dúvidas e anseios que as mulheres tinham em relação aos cuidados com o recém-nascido e consigo mesmas. Realizar as orientações às puérperas e famílias em alojamento conjunto possibilitou que as acadêmicas refletissem o quanto o papel do enfermeiro, enquanto educador em saúde, é fundamental para a manutenção do cuidado e empoderamento da mulher no autocuidado e cuidado com o recémnascido.
\end{abstract}

Palavras-chave: Alojamento conjunto; Cuidados de enfermagem; Educação em saúde.

\begin{abstract}
This study aimed to report an academic experience with puerperal women and family members in accommodation reflecting the importance of guidance on care for the newborn and the woman's selfcare. This is an experience report developed during the practical activities of the women's health discipline. For a theoretical basis on performance, it was carried out in search of the Latin American and Caribbean Literature in Health Sciences database. The academic experience made the students from the anamnesis and active listening realize the main doubts and anxieties that the women had in relation to the care of the newborn and I can follow. Carrying out guidelines to the puerperal women and families in joint accommodation allowed the students to reflect on how the role of the nurse, as a health educator, is fundamental for maintaining the care and empowerment of women in self-care and care for the newborn.

\footnotetext{
${ }^{1}$ Trabalho realizado na disciplina de Saúde da Mulher.

${ }^{2}$ Acadêmica do curso de Enfermagem da Universidade Regional Integrada do Alto Uruguai e das Missões URI-Câmpus de Santiago. E-mail: gabrielironzani.gr@gmail.com

${ }^{3}$ Acadêmica do curso de Enfermagem. Universidade Regional Integrada do Alto Uruguai e das Missões - URICâmpus de Santiago. E-mail: gloriabio1@gmail.com

${ }^{4}$ Enfermeira. Universidade Regional Integrada do Alto Uruguai e das Missões - URI-Santiago. E-mail: flaviacamefd@gmail.com

${ }^{5}$ Enfermeira. Mestre em Saúde Materno Infantil. Docente do Curso de Enfermagem da Universidade Regional Integrada do Alto Uruguai e das Missões - URI-Santiago E-mail: enfermeira.lenise@ gmail.com
} 


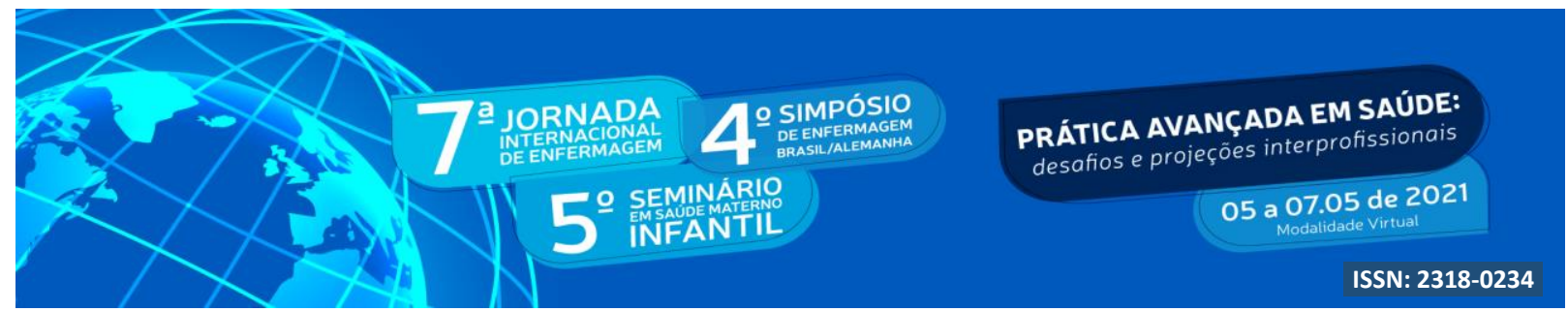

Key Words: Rooming-in; Nursing care; Health education.

\section{INTRODUÇÃO}

O puerpério, também conhecido como período pós-parto, inicia-se logo após a dequitação da placenta e se estende até o retorno dos órgãos reprodutores ao estado prégravídico. Neste período, ocorrem várias adaptações hormonais, psíquicas e metabólica no organismo da mulher (OLIVEIRA, 2012). Além disso, é nesse momento que a puérpera exerce atividades novas originadas da maternidade e do autocuidado. Em decorrência dessas transformações, é comum que surjam sentimentos ambíguos tais como: euforia e alívio; felicidade e medo; ansiedade e insegurança, indiferença e reconhecimento do filho; medo de não conseguir cuidar e atender as necessidades do recém-nascido (RN) e, dúvidas se será uma boa mãe (STRAPASSON, 2010).

Durante esse período, a puérpera torna-se emocionalmente vulnerável, demandando de cuidados e de uma rede de apoio estruturada por amigos, familiares e profissionais da saúde. No decorrer da hospitalização, os cuidados prestados pela equipe de enfermagem dirigem-se ao binômio mãe-bebê, atendendo de forma singular e integral as necessidades de ambos. (BARBOSA, 2005). Nesse contexto ainda, os familiares também recebem cuidados e atenção da enfermagem, pois entende-se que são eles as principais fontes de segurança a puérpera e que darão continuidade ao cuidado.

A eficácia da assistência de enfermagem se fará pela interação profissional-puérperafamília, baseada em uma atenção empática, sensível e humanística. O profissional que realiza a assistência a essa nova família precisa desenvolver uma escuta ativa e transmitir confiança e segurança a todos os envolvidos, pois isso contribuirá na formação do vínculo. Quando o vínculo é criado com a puérpera, esta sente-se mais segura na realização do autocuidado e do cuidado com o RN, pois sabe que estará amparada com um profissional de sua confiança (STREFLING, 2017).

A Assistência de Enfermagem no período puerperal é desenvolvida no Alojamento Conjunto (AC), modelo assistencial adotado no Brasil para o atendimento do binômio mãebebê. Este é definido pelo Ministério da Saúde como uma unidade hospitalar em que o RN 


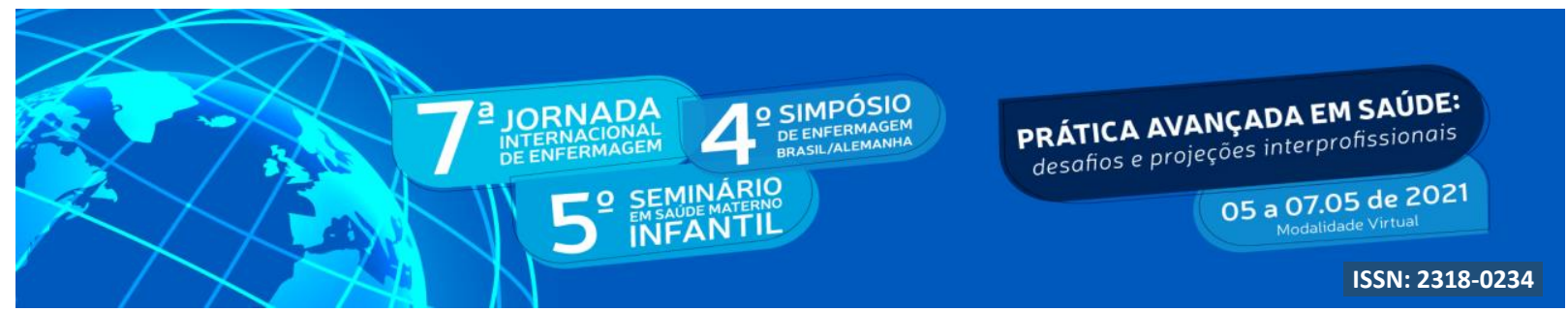

sadio logo após o nascimento fica ao lado da puérpera até a alta hospitalar. $\mathrm{O}$ alojamento conjunto é um ambiente onde irá ocorrer a interação mãe e filho, a construção dos laços afetivos, a preparação do ser mãe e pai, o fortalecimento de habilidades para o cuidado do $\mathrm{RN}$, estimulação, apoio e promoção do aleitamento materno (AM) e redução dos riscos de morbidades maternas e neonatais (MERCADO et al., 2017).

Durante a assistência de enfermagem é essencial que o binômio seja assistido em todos os aspectos da saúde, fisiológicos, psicológicos, emocionais, sociais, espirituais e culturais. Nesse sentido, o enfermeiro tem papel fundamental em assegurar uma assistência integral e de qualidade à puérpera/família/recém-nascido. Ainda, é agente multiplicador no tocante das orientações, realizando educação em saúde, promovendo o $\mathrm{AM}$, preparando a puérpera e a família para o cuidado com o RN, orientando sobre o autocuidado, retorno a vida sexual, planejamento reprodutivo, cuidados com o coto umbilical, higiene do RN, consulta de puerpério e puericultura e imunização do RN (MERCADO et al., 2017).

\section{OBJETIVO}

Relatar uma experiência acadêmica com puérperas e familiares em alojamento conjunto refletindo a importância das orientações sobre os cuidados com o recém-nascido e o autocuidado da mulher.

\section{METODOLOGIA}

Trata-se de um relato de experiência desenvolvido durante as atividades praticas da disciplina de saúde da mulher, em uma unidade hospitalar de alojamento conjunto, localizada em um hospital de médio porte da região centro-oeste do Estado do Rio Grande do Sul. A experiência ocorreu durante cinco dias e se desenvolveu no mês de fevereiro de 2021, por acadêmicas graduandas do Curso de Enfermagem de uma instituição filantrópica de Ensino Superior.

Para um embasamento teórico nas discussões foi realizada busca na Biblioteca Virtual em Saúde na base de dados Literatura Latino-americana e do Caribe em Ciências da Saúde 


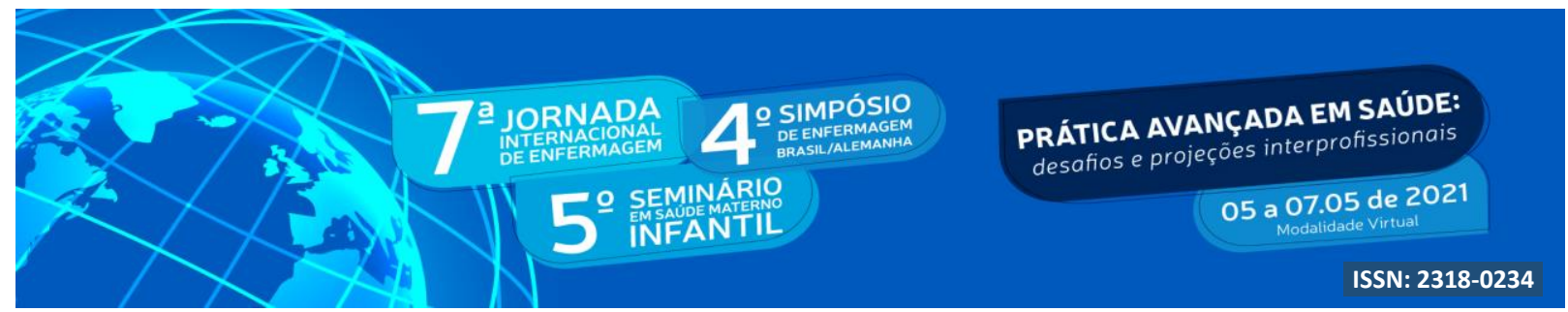

(Lilacs) com os descritores: "puerpério" and "enfermagem" and "saúde da mulher"; "puerperio" and "relações familiares"; "puerpério" and "alojamento conjunto"; "orientações" and "enfermagem" and "alojamento conjunto".

\section{RELATO DE EXPERIÊNCIA}

A assistência de enfermagem com as puérperas no alojamento conjunto fez com que as acadêmicas a partir da anamnese e da escuta ativa percebessem as principais dúvidas e anseios que as mulheres tinham em relação aos cuidados com o RN e consigo mesmas. Ainda, observaram a importância do respeito as questões culturais, valores e conhecimento da família.

Durante as práticas foram desenvolvidas atividades privativas do enfermeiro, cuidados de enfermagem no pós-parto imediato, cuidados com o recém-nascido em sala de parto e, promoção, incentivo e apoio ao aleitamento materno. Ainda, foram realizadas orientações de alta hospitalar, neste momento, participavam a puérpera e os pais e/ou familiares. As orientações eram referentes ao autocuidado da puérpera, retorno a vida sexual, consulta de puerpério e puericultura na atenção básica, importância da rede de apoio, retorno das atividades físicas e domiciliares, cuidados com a ferida operatória (FO), episiorrafia ou sutura da laceração, cuidados com o recém-nascido, cuidados com o coto umbilical, trocas de fralda e higiene do RN.

Estudos evidenciam que a família possui papel fundamental, trazendo bem-estar à puérpera e reduzindo o estresse da nova dinâmica. A formação da rede de apoio familiar é naturalmente baseada nos valores, crenças e conhecimentos passados de geração em geração. Tem-se cada vez mais verificado a importância da família durante o período puerperal, principalmente nas questões relacionadas ao aconselhamento, apoio e cuidado à puérpera e ao recém-nascido, pois entende-se que está dará continuidade ao cuidado. Nesse sentido, a participação da família no contexto da educação em saúde e das orientações são essenciais (PRATES et al., 2014; PISSOLATO et al., 2016; GLAVIN; WARREN, 2013).

A fim de oferecer uma assistência de qualidade o enfermeiro ao se aproximar da rede familiar da puérpera, precisa buscar conhecer os seus saberes e experiências. Dessa forma, o profissional consegue compreender o contexto onde a puérpera está inserida e realizar 


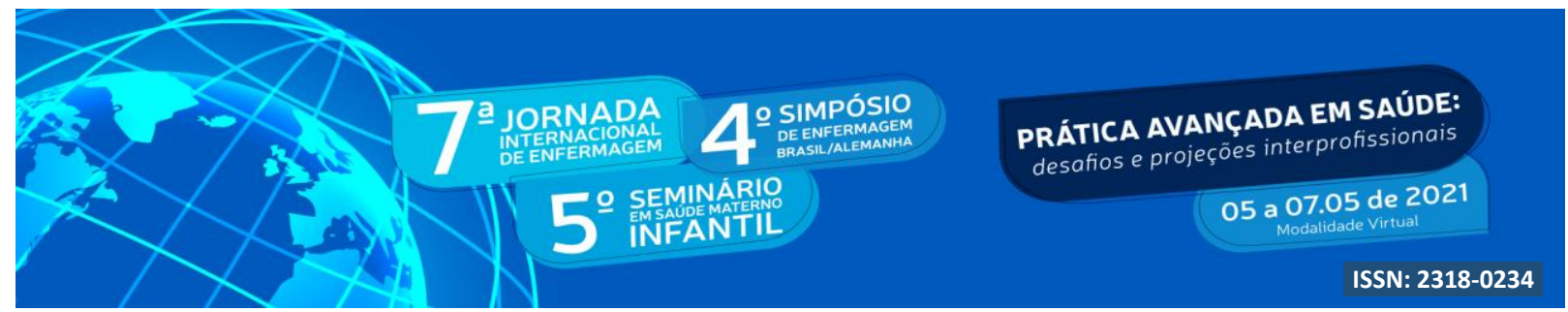

orientações pertinentes a essa realidade. Ainda, respeita a questão cultural familiar, mas agrega com seu conhecimento e práticas baseadas em evidência, vislumbrando a adesão e manutenção do cuidado ao binômio (PRATES et. al., 2014).

Percebeu-se, que independentemente do número de filhos as dúvidas existem e que muitos cuidados são passados de geração em geração, afirmando o quanto o contexto cultural, religioso são predominantes entre as famílias. Elucidando, surgiam dúvidas em relação ao uso do sabonete adequado na hora do banho, à frequência da limpeza do coto umbilical e se era necessário fazer uso de faixinha ou curativo no coto umbilical. Além disso, surgiram questionamentos sobre o autocuidado como, quando era possível lavar o cabelo, se ingerir cerveja preta aumentava produção de leite e se podia comer todo tipo de alimento.

As acadêmicas puderam observar também, o uso frequente de lenços umedecidos, pomadas para assadura e talcos durante as trocas de fralda, bem como, a posição dos dedos em "v" durante a amamentação, os medos que as mulheres têm do leite ser insuficiente ou fraco e o bebê ficar com fome, bem como o uso da chupeta antes das 24 h de vida do RN. Essas práticas vinham acompanhadas de inseguranças na hora do cuidado com o RN, na maior parte das vezes pela puérpera e pelo pai.

As orientações prestadas as puérperas e as famílias foram embasadas nas recomendações do Ministério da Saúde, o qual alerta que o uso da chupeta e da mamadeira é desaconselhado e pode interferir negativamente no aleitamento materno exclusivo. A frequência do uso do bico artificial diminui a produção de leite, causa alterações no palato e é fonte de contaminação, contribuindo para a candidíase e otite (BRASIL, 2015).

Ainda, observa que apesar de os lenços umedecidos de limpeza serem práticos e de cheiro agradável, não são recomendados em decorrência do risco de causar sensibilidade na pele do bebê, pois o contato continuo pode causar lesões a barreira cutânea, provocando dermatite de contato. $\mathrm{O}$ adequado é utilizar de água morna e fralda de pano para higienizar o bebê, e após seca-lo (FERNANDES; MACHADO; OLIVEIRA, 2011).

As acadêmicas puderam presenciar ainda, que após as orientações houveram adaptações e, muita satisfação por parte da puérpera e sua família. Os relatos das mulheres as acadêmicas eram principalmente referentes a melhora na amamentação, melhor compreensão dos cuidados com o recém-nascido, curativo da FO e uso da chupeta. Além disso, algumas informaram que apesar de terem outros filhos, aquelas informações eram novas e que almejavam colocá-las em 


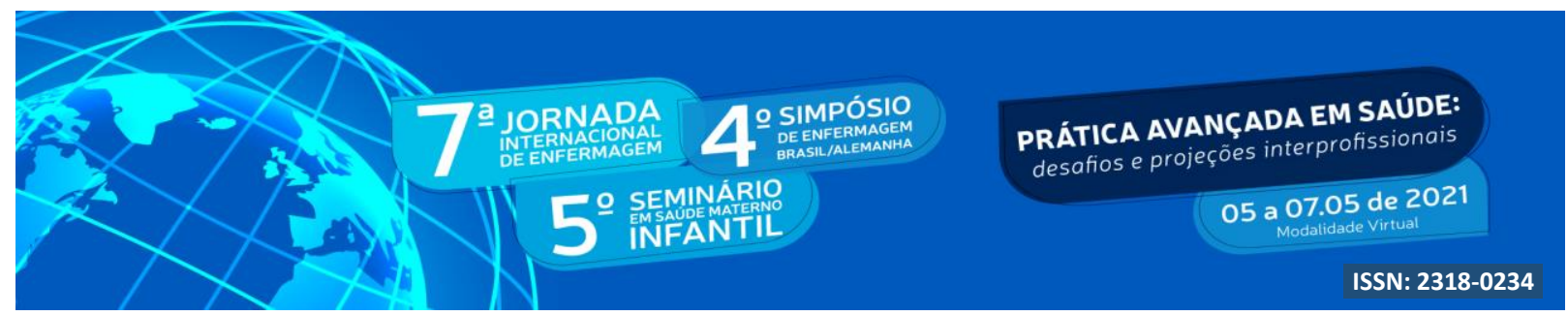

prática. O mesmo era relatado pelas avós, que apesar de se notar no início dos atendimentos um pouco de resistência, com o passar do tempo e com a criação do vínculo se sentiam atraídas a realizar as orientações fornecidas, bem como entusiasmadas em adquirir um novo conhecimento.

O nascimento de um filho desperta vários sentimentos na puérpera. Ao desempenhar a maternidade é normal a mulher, manifestar certo desconhecimento, habilidade insuficiente e se deparar com muitos afazeres para proporcionar o bem-estar do recém-nascido. Além disso, ao mesmo tempo que é mãe, também é puérpera, sendo fundamental um suporte multiprofissional, o qual oferecerá o cuidado necessário para o desenvolvimento da maternagem. Por meio deste, será possível empoderar a puérpera, a realizar o autocuidado e o cuidado com o RN (SILVA et. al., 2015; BERRI, 2019).

Ademais, cabe aos profissionais da saúde, em especial o profissional enfermeiro, realizar as primeiras orientações a puérpera, para que ela tenha autonomia para realizar estes cuidados com mais segurança e conhecimento. Desta forma, a assistência de enfermagem no puerpério imediato tem como finalidade oferecer estratégias de enfrentamento e adaptação à transição à maternidade, com iniciativas direcionadas para que as mães e familiares superem suas dificuldades e desenvolvam suas habilidades de cuidado (MARQUES et al., 2014).

\section{CONCLUSÃO}

Realizar as orientações as puérperas e famílias em alojamento conjunto possibilitou as acadêmicas refletirem o quanto o papel do enfermeiro, enquanto educador em saúde, é fundamental para a manutenção do cuidado e empoderamento da mulher no autocuidado e cuidado com o recém-nascido. Percebeu-se, ainda, o quanto um cuidado singular, integral, empático e humano pode contribuir para a redução de dores na amamentação e aumentar a confiança e segurança da puérpera na realização dos cuidados com o filho.

Ainda, contribuiu para que as acadêmicas percebessem a família como principal aliada no cuidado e apoio a puérpera, bem como redutora de estresse dessa dinâmica nova na vida das mulheres. Incluir a família no cuidado a puérpera e ao recém-nascido, ouvir o conhecimento e entender o contexto familiar possibilitou que se valorizasse ainda mais o cuidado sistêmico.

Estar enfermeiro em um período tão especial e único na vida de uma família, necessita de conhecimento teórico-prático, mas muito mais que isso presença para sentir e vivenciar esse 


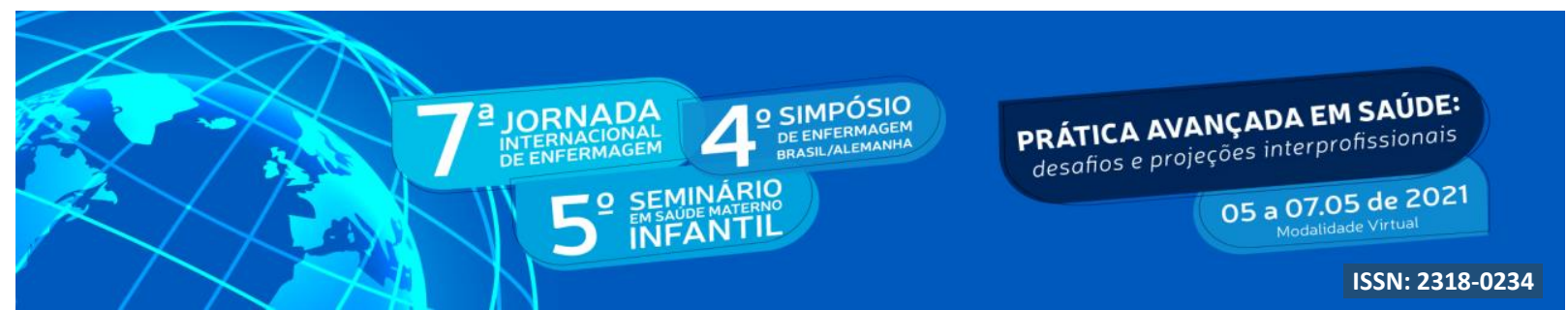

momento. Quando se está presente é possível sentir e ouvir mais atentamente as reais necessidades de uma mãe, seu filho e família, bem como favorece a criação do vínculo e aumenta a qualidade da assistência.

\section{REFERÊNCIAS}

BARBOSA, R. C. M. et al. Rede social de apoio à mulher no período puerperal. Revista Mineira de enfermagem, Minas Gerais, v. 9, n. 4, p. 361-366, 2005.

BERRI, B. $O$ cuidado à puérpera na instituição hospitalar: um relato de experiência. Florianópolis, 2019. Trabalho apresentado ao Curso da Residência Multiprofissional Integrada em Saúde da Universidade Federal de Santa Catarina.

BRASIL. Ministério da Saúde. Secretaria de Atenção à Saúde. Departamento de Atenção Básica. Saúde da criança: aleitamento materno e alimentação complementar - 2. ed. Brasília: Ministério da Saúde, 2015.

FERNANDES, J. D.; MACHADO, M. C.; OLIVEIRA, Z. N. Prevenção e cuidado com a pele da criança e do recém-nascido. An. Bras Dermatol, v. 86, n. 1, p. 102-110, 2011.

GLAVIN, K.; WARREN, P. L. Postnatal Depression Is a Public Health Nursing Issue: Perspectives from Norway and Ireland. Nurs Res Pract. 2013.

MARQUES, D. K. A. et al. Percepções de puérperas frente à assistência de enfermagem no alojamento conjunto. Rev. Ciênc. Saúde, Nova Esperança, v. 12, n. 1, p. 45-57, 2014.

MERCADO, N. C. et al. Cuidados e orientações de enfermagem ás puérperas no alojamento conjunto. Rev. Enferm. UFPE. Recife. v. 11, n. 9, p. 3508-15. Set. 2017. 


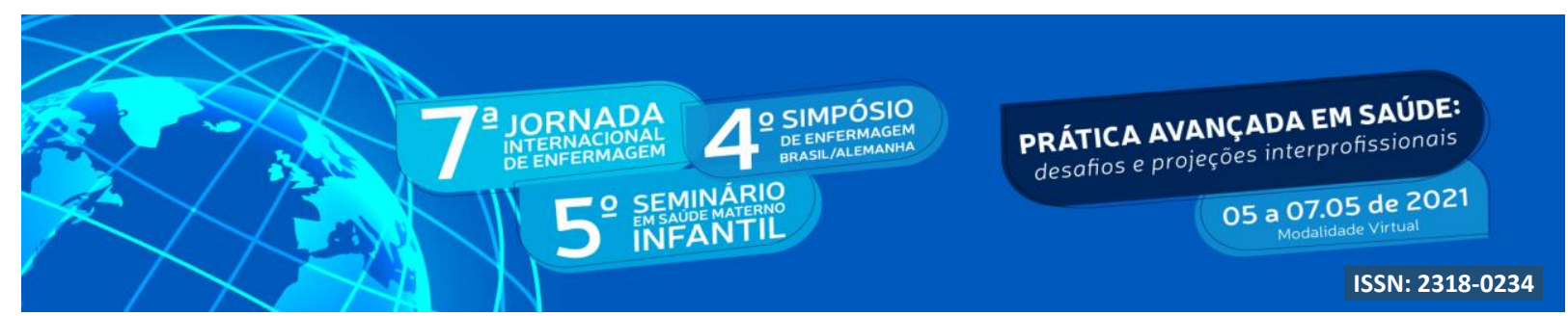

OLIVEIRA, J. F. B. de. Percepção das puérperas quanto aos cuidados prestados pela equipe de saúde no puerpério. Revista Rene, Ceará, v. 13, n. 1, p. 74-84, 2012.

PISSOLATO, L. K. B. P. et al. Amamentação e sexualidade: uma interface na vivência do puerpério. Rev Fund Care Online. v. 8, n. 3, p. 4674-80, jul/set, 2016. doi: http://dx.doi.org/10.9789/2175- 5361.2016.v8i3.4674-4680.

PRATES, L. A. et al. Amamentação: A influência familiar e o papel dos profissionais de saúde. Rev. de enferm. UFSM, .. 4, n. 2, p. 359-367, abr/jun, 2014.

SILVA, C. M. S. et al. Sentimentos vivenciados por puérperas na realização do primeiro banho do recém-nascido no alojamento conjunto. O Mundo da Saúde, [S.L.], v.39, n. 3, p. 279-286, 30 set. 2015. Centro Universitario Sao Camilo - Sao Paulo. doi: http://dx.doi.org/10.15343/0104-7809.20153903279286.

STRAPASSON, M. R.; NEDEL, M. N. B. Puerpério imediato: desvendando o significado da maternidade. Rev Gaúcha Enferm., Porto Alegre (RS) v. 31, n. 3, p. 521-8, set, 2010.

STREFLING, I. S. S. et al. Percepções de puérperas sobre o cuidado de enfermagem no alojamento conjunto. J. res. Fundam. Care. Online. v. 9, n. 2, p. 333-339. abr/jun. 2017. 